\title{
Effect of temperature on accumulation of chlorophylls and leaf ultrastructure of low temperature induced albino tea plant
}

\author{
Du, Y. Y., Chen, H., Zhong, W. L., Wu, L. Y., Ye, J. H., Lin, C., Zheng, X. Q., Lu, J. L. and \\ Liang, Y. R.*
}

Zhejiang University Tea Research Institute, 268 Kaixuan Road, Hangzhou 310029, China.

Accepted 11 April, 2008

\begin{abstract}
White young shoots from albino tea cultivars have high level of amino acids and are rare and valuable materials for processing green tea. The effects of temperature on leaf colour, accumulation of chlorophylls and leaf ultrastructures of an albino tea cultivar 'Xiaxueya' were investigated. The study showed that the shoot albino phenomenon of 'Xiaoxueya' was controlled by temperature. The development of chloroplast from etioplast and the accumulation of chlorophylls $a$ and $b$ were blocked and albino shoots were observed at $15^{\circ} \mathrm{C}$. However, the albino phenomenon was reversed when the plant was grown at $20^{\circ} \mathrm{C}$ or above. The authors recommended that the albino tea cultivars should be grown at high altitude or high latitude areas so as to prolong the production season of albino tea shoots.
\end{abstract}

Key words: Camellia sinensis, albino tea, chloroplast, etioplast, colour difference, amino acids.

\section{INTRODUCTION}

There are great genetic variations in tea germplasm (Wachira et al., 2001), in which albino tea cultivars have white young shoots and high level of amino acids than their green counterparts (Du et al., 2006). There are two types of albino tea mutant found in China. One is controlled by temperature, which has white shoots when the environmental temperature was below $20^{\circ} \mathrm{C}$ during early spring season. The other is controlled by light illumination, which has albino shoots in strong sunlight summer season (Du et al., 2006). The former has been widely grown in China, especially in Zhejiang Province.

Chemical composition is an important determinant of sensory quality of tea and healthy effects (Liang et al., 2005; Oyejide and Olushola, 2005; Karori et al., 2007; Mbata, 2007; Wang and Li, 2006). The albino tea cultivar has very high concentration of amino acids, especially theanine which is a unique amino acid found exclusively in tea (Konishi and Takahashi, 1969; Du et al., 2006). Many amino acids have palatable taste and are important contributor to sensory quality of green tea (Liang et al.,

${ }^{*}$ Corresponding author. E-mail: yrliang@zju.edu.cn. Fax: +86 57186971704.
1996). Theanine has recently received much attention due to its health benefits such as promoting relaxation, reducing stress and anxiety, improving memory and learning ability, as well as suppressing high blood pressure (Yokogoshi et al., 1995; Juneja et al., 1999; Kakuda, 2002; Kim et al., 2004; Zhang et al., 2007). Owing to its special quality and healthy potential, good tea products prepared from the albino tea cultivars are in great demand.

However, the albino tea plants are very sensitive to environmental conditions, resulting in instability of chemical composition of the albino tea products. For example, 'White leaf No.1', a low temperature induced albino tea cultivar, has white shoots and high concentration of amino acids when environmental temperature is below $20^{\circ} \mathrm{C}$, but the albino phenomenon disappears when the temperature is above $20^{\circ} \mathrm{C}$, resulting sharp decrease in amino acids level. Though physiological characteristics in some albino plants were partially revealed (Yang et al., 2005), little information about the physiological mechanism of albino tea plant has been available.

In the present study, a low temperature induced albino tea cultivar 'Xiaoxueya' was used to examine the impact of temperature on leaf colour, accumulation of photosynthesis related pigments, and leaf ultrastructures, with 
Table 1. Hunter colour parameters $L$, $a$ and $b$ of leaves at different temperatures *.

\begin{tabular}{|l|c|c|c|c|}
\hline Tea cultivar & Temperature & $\mathbf{L}$ & $\mathbf{a}$ & $\mathbf{b}$ \\
\hline Fudingdabai & $15^{\circ} \mathrm{C}$ & $35.83 \pm 3.77$ & $-19.06 \pm 1.66$ & $12.75 \pm 1.94$ \\
& $20^{\circ} \mathrm{C}$ & $37.75 \pm 1.76$ & $-14.92 \pm 1.47$ & $13.92 \pm 2.38$ \\
& $25^{\circ} \mathrm{C}$ & $41.23 \pm 2.90$ & $-16.53 \pm 0.17$ & $16.39 \pm 1.60$ \\
\hline Xiaoxueya & $15^{\circ} \mathrm{C}$ & $88.76 \pm 2.15$ & $-0.28 \pm 1.28$ & $30.49 \pm 3.46$ \\
& $20^{\circ} \mathrm{C}$ & $36.46 \pm 0.82$ & $-13.52 \pm 0.90$ & $12.11 \pm 0.42$ \\
& $25^{\circ} \mathrm{C}$ & $41.23 \pm 2.90$ & $-16.53 \pm 0.17$ & $16.39 \pm 1.60$ \\
\hline
\end{tabular}

*Values followed by a different lower-case letter in a same column are statistically different at $P=0.05(n=5)$.

comparison to a normal tea cultivar 'Fudingdabai', in order to understand the albino mechanism of the tea mutant and provide useful information for developing agricultural techniques to improve its cultivation.

\section{MATERIALS AND METHODS}

\section{Growth of tea plants}

One year old cuttings of albino tea cultivar (Camellia sinensis cv. 'Xiaoxueya') and normal green tea cultivar (Camellia sinensis cv. 'Fudingdabai') were used in the experiment. The plants were planted in plastic pot $(20 \mathrm{~cm}$ in diameter and $25 \mathrm{~cm}$ in height, two plants each pot) with a medium of compost and yellow earth $(1: 2, \mathrm{v} / \mathrm{v})$ in late October, 2006. Each cultivar was planted in fifteen pots. The plants (five pots each treatment) were placed in model ZRX-1000DC illumination incubators (Qianjiang Instrument Equipment Co. Ltd, Hangzhou, China) at 15,20 and $25^{\circ} \mathrm{C}$, respectively. Photoperiod of illumination incubators was $12 \mathrm{~h}$ white light $\left(45 \mu \mathrm{mol} \mathrm{m}^{-2} \mathrm{~s}^{-1}\right)$ and 12 $h$ dark. Second leaf from apical bud was sampled for testing in late July, 2007.

\section{Determination of leaf color}

The leaf color was determined using a TC-PIIG automatic color difference meter (Beijing Optical Instrument Factory, Beijing, China) according to the method describe by Liang et al. (2003). Color parameters of $L, a$ and $b$, which represent the lightness-darkness, redness-greenness and yellowness-blueness on the three dimensional Hunter $L$, $a, b$ uniform colour scale respectively, were printed out directly by the color difference meter.

\section{Determination of chlorophylls}

Fresh leaf $(0.2 \mathrm{~g})$ was ground into paste with $10 \mathrm{ml}$ cool acetone and centrifuged at $4,300 \times \mathrm{g}$ at $4^{\circ} \mathrm{C}$ for $10 \mathrm{~min}$. The supernatant was then used for HPLC analysis. The HPLC was carried out in the following conditions: Shimadzu 2010 HPLC (Shimadzu Co. Ltd., Kyoto, Japan), injection volume $10 \mu \mathrm{L}$, Shimadzu CLC-ODS column $6.0 \mathrm{~mm} \varnothing \times 0.15 \mathrm{~m}$, column temperature $30^{\circ} \mathrm{C}$, linear gradient from $100 \%$ mobile phase $A$ (acetonitrile: acetic acid: water $=6: 1: 193$, $\mathrm{v} / \mathrm{v} / \mathrm{v}$ ) to $100 \%$ mobile phase $\mathrm{B}$ (acetonitrile: methanol: chloroform = $150: 40: 10, \mathrm{v} / \mathrm{v} / \mathrm{v})$ in $20 \mathrm{~min}$, flow rate $1 \mathrm{~mL} \mathrm{~min}^{-1}$. The eluate was monitored at $450 \mathrm{~nm}$ using a Shimadzu SPD ultraviolet detector (Shimadzu Co. Ltd., Kyoto, Japan). Qualitative and quantitative analysis of chlorophyll $a$ and chlorophyll $b$ were carried out by comparing retention time and peak height of samples with those of authentic compounds of chlorophyll a and chlorophyll b (Wacay International Inc. Rowland Heights, CA, USA).

\section{Transmission of electron microscopy (TEM)}

Tea leaf was fixed in glutaraldehyde solution (2.5\%) overnight at $4^{\circ} \mathrm{C}$. The solution was poured out and the leaf was washed with $0.1 \mathrm{M}$ phosphate buffer ( $\mathrm{pH} 7.0$ ) for three times (15 min each washing). The leaf was re-fixed in $1 \%(\mathrm{v} / \mathrm{v}) \mathrm{OsO} 4$ solution for $2 \mathrm{~h}$ and washed using with $0.1 \mathrm{M}$ phosphate buffer as before. The fixed leaf was dehydrated in a graded series of ethanol (50, 70, 80, 90, 95 and $100 \%$ ). Each dehydration step lasted $15 \mathrm{~min}$. The dehydrated leaf was drenched sequentially in acetone for $1 \mathrm{~h}$, in epoxy resin and acetone $(1: 1, v / v)$ for $3 h$, epoxy resin and acetone $(3: 1, v / v)$ for $3 \mathrm{~h}$ at room temperature. The leaf was finally embed in pure epoxy resin overnight at $70^{\circ} \mathrm{C}$. Sections of $70-90 \mathrm{~nm}$ thickness were made on a Reichert-Jung ultra-cut 701701 microtome (Reichert-Jung Co., Heidelburg, Germany). The sections were examined and photographed with a JEM-1230 microscope (JEOL Ltd. Akishima, Tokyo, Japan).

\section{RESULTS AND DISCUSSION}

\section{Leaf colour at various temperatures}

Parameters of $L, a$ and $b$ are indicators to discriminate the visual differences of lightness-darkness, rednessgreenness and yellowness-blueness on the three dimensional Hunter $L, a, b$ uniform colour scale, respectively. The Hunter $L, a, b$ colour space is organized in a cubic form. The $L$ axis runs from top to bottom and the maximum $L$ is 100 , which is a perfect reflecting diffuser. The minimum for $L$ is zero, which is black. The $a$ and $b$ axes have no specific numerical limits. Positive $a$ is red and negative $a$ is green. Positive $b$ is yellow and negative $\mathrm{b}$ is blue. Table 1 showed that albino cultivar 'Xiaoxueya' at $15^{\circ} \mathrm{C}$ had the highest values of $\mathrm{L}, \mathrm{a}$ and $b$ among all the treatments including different cultivars and temperatures, suggesting that leaf of 'Xiaoxueya' at $15^{\circ} \mathrm{C}$ was the most diffuse, the lightest in green colour and the deepest in yellow colour. It also indicates that the albino phenomenon of 'Xiaoxueya' was induced by low temperature such as $15^{\circ} \mathrm{C}$ and the albino phenomenon was reversible when temperature was increased.

Figure 1 confirmed that the albino phenomenon of 'Xiaoxueya' was observed at $15^{\circ} \mathrm{C}$ but it was reversed when temperature was increased to $20^{\circ} \mathrm{C}$ (Figure $1 \mathrm{~A}$ and $B)$. When the temperature was increased to $25^{\circ} \mathrm{C}$, the leaf of 'Xiaoxueya' was as green as the normal ciltivar 'Fudingdabai'. However, the leaf colour of normal cultivar 
Table 2. Concentrations of chlorophylls at various temperatures ( $\mu \mathrm{g} \mathrm{g}^{-1}$, fresh weight).

\begin{tabular}{|l|c|c|c|c|c|c|}
\hline \multirow{2}{*}{ Chlorophyll } & \multicolumn{3}{|c|}{ Fudingdabai } & \multicolumn{3}{c|}{ Xiaoxueya } \\
\cline { 2 - 7 } & 15C & 20C & 25C & 15C & 20C & 25C \\
\hline Chlorophyll b & $137.09+4.88$ & $243.80+38.67$ & $377.53+6.00$ & $5.13+0.79$ & $182.13+23.38$ & $322.61+6.19$ \\
Chlorophyll a & $384.30+12.66$ & $872.93+70.22$ & $919.07+5.35$ & $10.34+2.32$ & $440.04+38.32$ & $878.92+28.58$ \\
Chlorophyll (a+b) & 521.39 & 1116.73 & 1296.6 & 15.47 & 622.17 & 1201.53 \\
a/b* & 2.8 & 3.58 & 2.43 & 2.02 & 2.42 & 2.72 \\
\hline
\end{tabular}

${ }^{*} \mathrm{a} / \mathrm{b}$ : The ratio of chlorophyll a to chlorophyll b
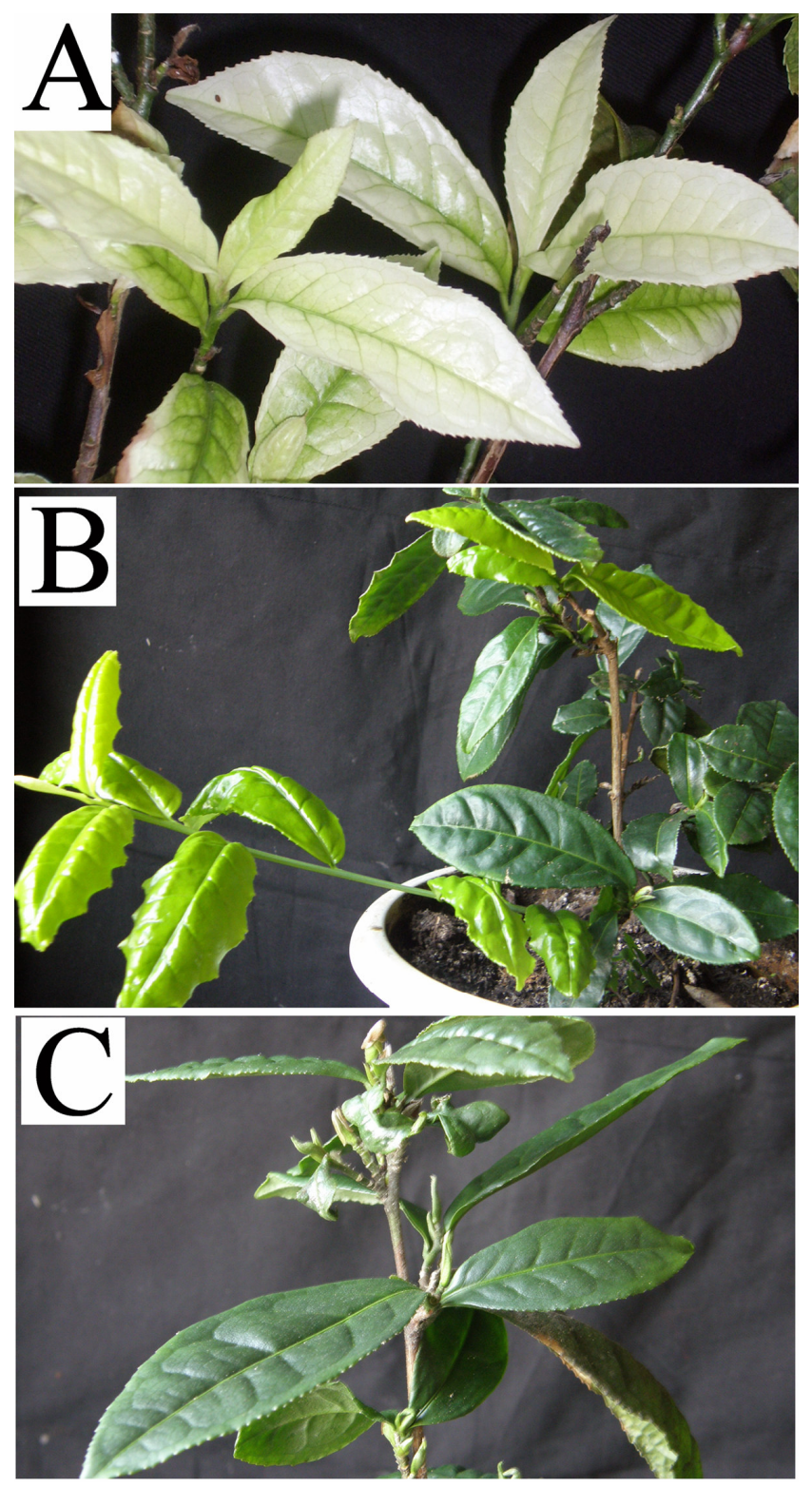

Figure 1. Leaf colour of two tea cultivars at different temperatures. A. 'Xiaoxuya' at $15^{\circ} \mathrm{C}$; B. 'Xiaoxueya' at $20^{\circ} \mathrm{C}$; C. 'Fudingdabai' at $15^{\circ} \mathrm{C}$.

'Fudingdabai' did not show abnormity usually at $15^{\circ} \mathrm{C}$ (Figure 1C).

\section{Concentrations of chlorophylls at various temperatures}

Table 2 showed that levels of chlorophylls $a$ and $b$ of 'Xiaoxueya' at $15^{\circ} \mathrm{C}$ were significantly lower than those of itself at 20 and $25^{\circ} \mathrm{C}$ and normal cultivar 'Fudingdabai' at the three temperatures tested. The results were consistent with the Hunter colour parameters in Table 1. This suggests that albino phenomenon of 'Xiaoxueya' was related to blockade in biosynthesis or accumulation of chlorophylls. The ratios of chlorophyll a to chlorophyll $b$ was lowest in leaf of 'Xiaoxueya' at $15^{\circ} \mathrm{C}$, suggesting that the blockade in biosynthesis or accumulation of chlorophyll a was more at $15^{\circ} \mathrm{C}$ than at the elevated temperatures.

\section{Leaf ultrastructures at various temperatures}

Chloroplast of normal cultivar 'Fudingdabai' did not show any abnormalities on ultrastructure when the plants grown at 15,20 and $25^{\circ} \mathrm{C}$. Its chloroplast showed the typical ultra-structures, which had chloroplast grana, stroma, thylakoids and one or two starch granules (Figure 1A).

Leaf ultrastructures cultivar 'Xiaoxueya' grown at 15, 20 and $25^{\circ} \mathrm{C}$ were different. The number of chloroplasts in the leaf cells reduced with decrease in temperature and mature chloroplast with full structures was not found in leaf grown at $15^{\circ} \mathrm{C}$ (Figure 2B1). Chloroplast is developed from etioplast (Balakrishna et al., 1999). In leaf of 'Xiaoxueya' grown at $15^{\circ} \mathrm{C}$, etioplasts were observed though mature chloroplast was not found (Figure 2B1). However, the observed etioplasts lacked thylakoid membranes and granal stacking ((Figure 2B2). The thylakoid membranes and granal stacking are typical structures in photosynthetically active chloroplasts. This suggests that the etioplast-chloroplast transition in leaves of 'Xiaoxueya' at $15^{\circ} \mathrm{C}$ was blocked.

Fully developed chloroplasts were observed in leaf of 'Xiaoxueya' grown at $20^{\circ} \mathrm{C}$ (Figure $2 \mathrm{C} 1$ ). The thylakoid membranes and granal stacking of the chloroplasts showed no abnormity (Figure $2 \mathrm{C} 2$ ). In leaf of 'Xiaoxueya' grown at $25^{\circ} \mathrm{C}$, the structures of chloroplasts looked the same as those at $20^{\circ} \mathrm{C}$, except that more chloroplasts were found (Figure 2D1-2). This indicates that the development of chloroplast from etioplast in leaf of albino 

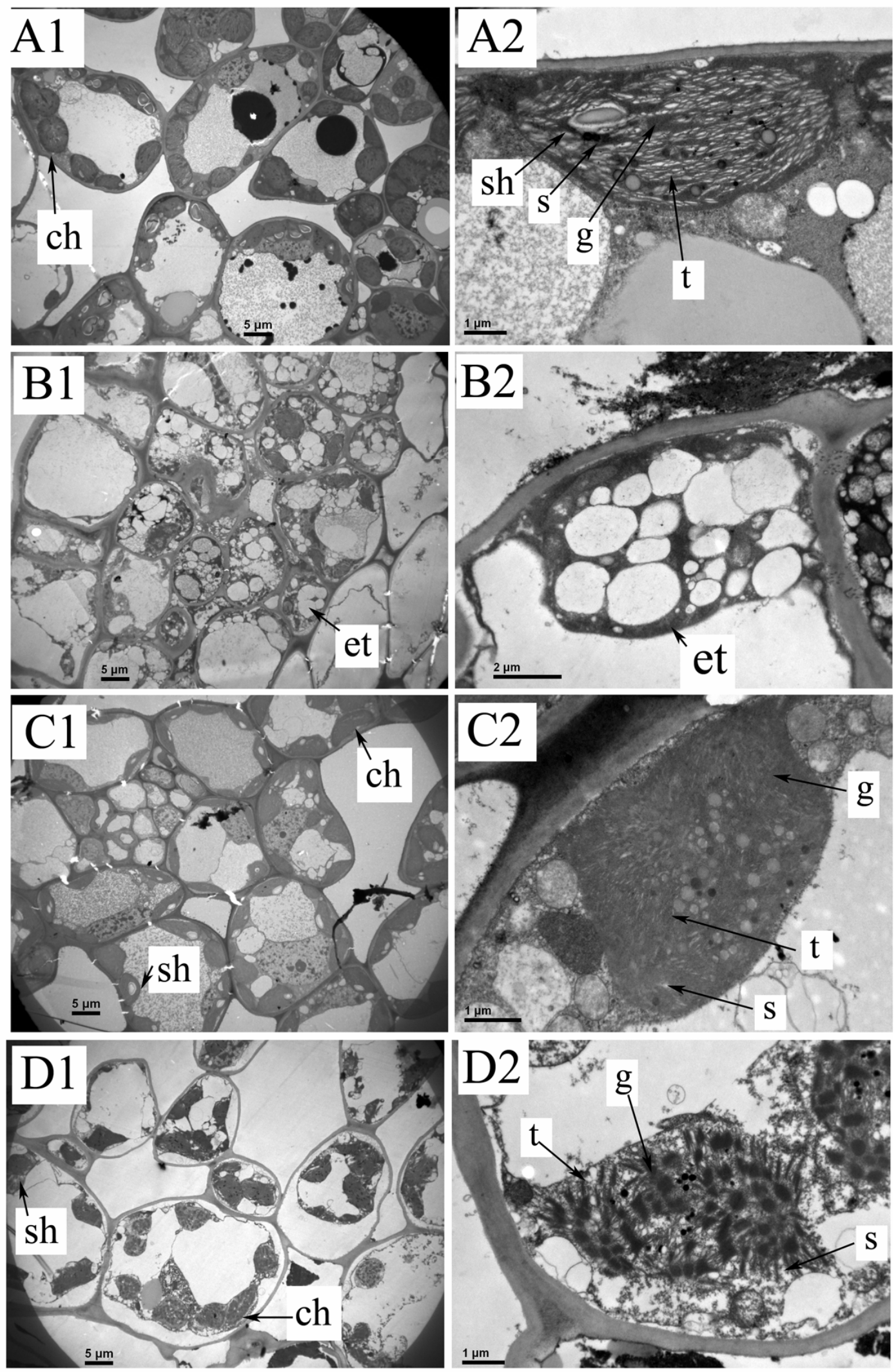

Figure 2. Ultrastructures of leaves of two tea cultivars at different temperatures

A. 'Fudingdabai' at $15^{\circ} \mathrm{C}$; B. 'Xiaoxueya' at $15^{\circ} \mathrm{C}$; C. 'Xiaoxueya' at $20^{\circ} \mathrm{C}$; D. 'Xiaoxueya' at $25^{\circ} \mathrm{C}$. ch: chloroplast; et: etioplast; sh: starch granule; g: grana; s: stroma; t: thylakoid. 
tea cultivar 'Xiaoxueya' is dependent on the temperature. Aberrant development of chloroplasts was paralleled by impairment of chlorophyll biosynthesis (van Hasselt and strikwerda, 1976; Hodgins and van Huystee, 1986), resulting in deficiency in pigments (Fambrini et al., 2004). Because chlorophylls are accumulated in the thylakoid membranes in the chloroplast, the arrested development of these membranes would block chlorophyll accumulation in the albino tea cultivar 'Xiaoxueya'. This explains why the albino phenomenon of cultivar 'Xiaoxueya' appears in the early spring season when the temperature is low and the albino phenomenon is reversible in the late season of the year when temperature increases.

The albino tea cultivar is considered to be rare and precious tea germplasm because of its high level of amino acids in its albino shoots. The problem in the production of the albino tea is that the albino phenomenon and chemical composition are changeable. The present study showed that the leaf colour, chlorophylls concentration and chloroplast ultrastructures which are closely related to the albino phenomenon were dependent on temperature. During harvesting season, if the duration of environmental temperature of $15^{\circ} \mathrm{C}$ is prolonged, the quantity and quality of albino tea shoots produced by the albino tea cultivar could be increased. It might be a good choice to plant the albino tea cultivars at high altitude or high latitude areas so as to increase the yield of albino tea shoots.

In higher plants, carotenoids are essential components of the photosynthetic apparatus and they were involved in light harvesting and protection against excessive light energy (Niyogi, 1999). Carotenoids were confirmed to be related to the formation of aromatic volatiles (Borthakur et al., 2008) but the relation of carotenoids level to the albino phenomenon is unknown. It will be helpful to further understand the albino mechanism of the low temperature induced albino tea cultivar in relationship to the biosynthesis of carotenoids and development of the photosynthetic apparatus. This remains to be further investigated.

\section{ACKNOWLEDGEMENT}

The present study was financially supported by the National Science Foundation of China (project No. 30771374).

\section{REFERENCES}

Balakrishna K, Joshi MK, Vani B, Mohanty P (1999). Structure-function correlation during the etioplast-chloroplast transition in cucumber cotyledonary leaves. Photosynthetica. 36: 199-212.

Borthakur D, Lu JL, Chen H, Lin C, Du YY, Liang YR (2008). Expression of phytoene synthase (psy) gene and its relation with accumulation of carotenoids in tea [Camellia sinensis $(\mathrm{L}) \mathrm{O}$ Kuntze]. Afr. J. Biotechnol. 7: $434-438$
Du YY, Liang YR, Wang H, Wang KR, Lu JL, Zhang GH, Lin WP, Li M, Fang QY (2006). A study on the chemical composition of albino tea cultivars. J. Hort. Sci. Biotechnol. 81: 809-812.

Fambrini M, Castagna A, Vecchia FD, Degl'Innocenti E, Ranieri A, Vernieri P, Pardossi A, Guidi L, Rascio N, Pugliesi C (2004). Characterization of a pigment-deficient mutant of sunflower (Helianthus annuus L.) with abnormal chloroplast biogenesis, reduced PS II activity and low endogenous level of abscisic acid. Plant Sci. 167: 79-89.

Hodgins R, van Huystee RB (1986). Porphyrin metabolism in chill stressed maize (Zea mays L.). J. Plant Physiol. 125: 325-336.

Juneja LR, Chu DC, Okubo T, Nagato Y, Yokogoshi H (1999). L-theanine - a unique amino acid of green tea and its relaxation effect in humans. Trend. Food Sci. Technol. 10: 199-204.

Kakuda T (2002). Neuroprotective effects of the green tea components theanine and catechins. Biol. Pharm. Bull. 25: 1513-1518.

Karori SM, Wachira FN, Wanyoko, JK, Ngure, RM (2007). Antioxidant capacity of different types of tea products. Afr. J. Biotechnol. 6: 2287-2296

Kim KS, Song $\mathrm{CH}$, Oh HJ (2004). Effects of theanine on the release of brain alpha-wave in adult males. FASEB J. 18 (Suppl. 4): A541-A542.

Konishi S, Takahashi E (1969). The metabolism and regulation of theanine and related compounds in tea plant. J. Sci. Soil Manure Jpn. 40: $479-484$

Liang YR, Lu JL, Shang SL (1996). Effect of gibberellins on chemical composition and quality of tea (Camellia sinensis). J. Sci. Food Agric. 72: 411-414.

Liang YR, Lu JL, Zhang LY, Wu S, Wu Y (2003). Estimation of black tea quality by analysis of chemical composition and colour difference of tea infusions. Food Chem. 80: 283-290.

Liang YR, Zhang LY, Lu JL (2005). A study on chemical estimation of pu-erh tea quality. J. Sci. Food Agric. 85: 381-390.

Mbata TI (2007). Preliminary studies of the antibacterial activities of processed Kenyan and Nigerian tea. Afr. J. Biotechnol. 6: 278-279.

Niyogi KK (1999). Photoprotection revisited: genetic and molecular approaches. Annu. Rev. Plant Physiol. Plant Mol. Biol. 50: 333-359.

Oyejide OO, Olushola L (2005). Hepatoprotective and antioxidant properties of extract of Carmellia sinensis (black tea) in rats. Afr. J. Biotechnol. 4: 1432-1438.

van Hasselt PR, Strikwerda JT (1976). Pigment degradation in discs of the thermophilic Cucumis sativus as affected by light, temperature, sugar application and inhibitors. Plant Physiol. 37: 253-257.

Wachira F, Tanaka J, Takeda Y (2001). Genetic variation and differentiation in tea (Camellia sinensis) germplasm revealed by RAPD and AFLP variation. J. Hort. Sci. Biotechnol. 76: 557-563.

Wang C, Li Y (2006). Research progress on property and application of Theaflavins. Afr. J. Biotechnol. 5: 213-218.

Yang MT, Chen SL, Lin CY (2005). Chilling stress suppresses chloroplast development and nuclear gene expression in leaves of mung bean seedlings. Planta. 221: 374-385.

Yokogoshi H, Kato Y, Sagesaka YM, Matsuura TT, Kakuda T, Takeuchi $N$ (1995). Reduction effect of theanine on blood pressure and brain 5 -hydroxyindoles in spontaneously hypertensive rats. Biosci. Biotechnol. Biochem. 59: 615-618.

Zhang GH, Liang YR, Jin J, Lu JL, Borthakur D, Dong JJ, Zheng XQ (2007). Induction of hairy roots by Agrobacterium rhizogenes in relation to L-theanine production in Camellia sinensis. J. Hort. Sci. Biotechnol. 82: 636-640. 